\title{
A recipe for future research
}

\author{
C. Klass, K. Wanyonyi, S. White, A. D. Walmsley, N. Hunt and J. E. Gallagher \\ Rapid Review Steering Group
}

The BDJ Upfront section includes editorials, letters, news, book reviews and interviews. Please direct your correspondence to the News Editor,

Kate Quinlan at BDJNews@nature.com. Press releases or articles may be edited, and should include a colour photograph if possible.

S o what is the link between oral and general health? This has been the cause of on-going debate across the health arena resulting in some grand statements, which may or may not be underpinned by evidence. The need to consider the evidence base and its gaps prompted Public Health England (PHE) to set up a review of current evidence which will also inform future research and its subsequent translation into healthcare practice.

Rapid reviews, in comparison with systematic reviews, provide a quick streamlined approach to synthesising evidence. ${ }^{1}$ They may include broad questions and use descriptive summary/categorisation of the data, as opposed to qualitative summary $+/$ - meta-analysis. ${ }^{1}$ Whilst both involve rigor and critical appraisal, systematic reviews are best for addressing focused questions and take longer.

A steering group led by King's College London Dental Institute (KCLDI) was formed of players from PHE, the Faculty of Dental Surgery of the Royal College of Surgeons of England and the British Dental Association. Topic areas focused on four of the top global diseases; diabetes mellitus, pulmonary disease, dementia and cardiovascular disease, while recognising that many other areas including kidney and liver disease, rheumatoid arthritis, stillbirth and mental health would also benefit from further inquiry.

- Cardiovascular disease (CVD): affects around 7 million people in the UK and is a significant cause of disability and death. ${ }^{2}$ Despite a significant reduction in deaths from CVD in the past 20 years, it remains the leading cause of disability years of life lost in England, ${ }^{3}$ and the second highest cause of death in England being responsible for $26 \%$ of all deaths in the UK; nearly 160,000 deaths each year ${ }^{2}$

- Diabetes: Affects around 3.8 million people aged 16 years and over (diagnosed and undiagnosed), equal to $8.6 \%$ of the population of this age group. Although mortality rates from diabetes have fallen, the prevalence of people with disability years of life lost is rising. ${ }^{3}$

- Pulmonary disease (inc. common obstructive pulmonary disease [COPD]): COPD is seen in around $2 \%$ of the population (at all ages), ${ }^{4}$ and is the fourth most common cause of death and years of life lost in England. ${ }^{3}$ Pneumonia was the cause of $5 \%$ of all deaths in $2014^{5}$ ten years using an established methodology and report on the following:

- Whether or not an association was demonstrated in the literature

- The nature and strength of association

- Whether any association is uni- or bi-directional

- If the dental management of oral diseases has an effect on the manifestation of the systemic disease and vice versa

- Implications for future research.

\section{'Rapid reviews provide a quick streamlined approach to synthesising evidence...'}

- Dementia: Currently found in approximately 1 in 14 of the UK population over 65 years and is expected to affect over 1 million people by $2025 .^{6}$

Three of the four topic areas that were selected are long-term conditions characterised by major mortality and morbidity in the UK. These serious diseases not only have implications for the patient, but also cost implications for the health service. Therefore, if oral health impacts on these diseases, it is appropriate to understand the nature and extent of relationships .

Task groups were set up for each of the four disease areas including a medical and dental consultant/specialist, PHE representative and two members of junior staff, all supported by the research team at KCL. Additionally, this project has provided junior staff with the opportunity to search and appraise the literature, extract data and synthesise the findings - all good specialty training! All task groups were asked to review the published literature over the preceeding
The reviews are published as a series of four papers in this Journal, starting with CVS, with a supporting fact sheet from PHE to follow. Their publication will act as a call to arms for researchers, within and beyond the dental community, and inform professional practice.

DOI: $10.1038 /$ sj.bdj.2017.192

1. Khangura S, Konnyu K, Cushman R, Grimshaw J, Moher $D$. Evidence summaries: the evolution of a rapid review approach. Syst Rev 2012; 1: 10.

2. British Heart Foundation. Cardiovascular disease statistics 2015 Nuffield Department of Population Health, University of Oxford: British Heart Foundation Centre on Population Approaches for Non-Communicable Disease Prevention. 2015. Available online at https://www.bhf. org.uk/publications/statistics/cvd-stats-2015.

3. Newton JN, Briggs ADM, Murray CJL, Dicker D, Foreman $\mathrm{KJ}$, Wang $\mathrm{H}$, et al. Changes in health in England, with analysis by English regions and areas of deprivation, 1990-2013: a systematic analysis for the Global Burden of Disease Study 2013. Lancet 2015; 386: 2257-74.

4. Public Health England. Public Health Profiles: Inhale INteractive Health Atlas of Lung conditions in England London. PHE. Available online at from http://fingertips. phe.org.uk/ (accessed February 2017).

5. Statistics OfN. Mortality Statistics: Deaths Registered in England and Wales (Series DR), 2014. London, 2014.

6. Prince $M$, Albanese $E$, Guerchet $M$, Prina M. World Alzheimer Report 2015. The Global Impact of Dementia: An analysis of prevalence, incidence, cost and trends, 2014. London: Altzheimers Disease International, 2015. 